\title{
Impact of cold temperatures on the shear strength of Norway spruce joints glued with different adhesives
}

\author{
Xiaodong Wang • Olle Hagman · Bror Sundqvist • \\ Sigurdur Ormarsson $\cdot$ Hui Wan $\cdot$ Peter Niemz
}

Received: 3 May 2014/Published online: 7 February 2015

(C) Springer-Verlag Berlin Heidelberg 2015

\begin{abstract}
As wood construction increasingly uses engineered wood products worldwide, concerns arise about the integrity of the wood and adhesives used. Bondline strength is a crucial issue for engineered wood applications, especially in cold climates. In this study, Norway spruce (Picea abies) joints $(150 \mathrm{~mm} \times 20 \mathrm{~mm} \times 10 \mathrm{~mm})$ were bonded with seven commercially available adhesives: polyurethane (PUR), polyvinyl acetate (PVAc), emulsion-polymer-isocyanate (EPI), melamine-formaldehyde (MF), phenol-resorcinol-formaldehyde (PRF), melamine-urea-formaldehyde1 (MUF1), and melamine-urea-formaldehyde2 (MUF2). Each adhesive was tested at six temperatures: $20,-20,-30,-40$, -50 and $-60{ }^{\circ} \mathrm{C}$. Generally, within the temperature test range, temperature changes significantly affected the shear strength of solid wood and wood joints. As the temperature decreased, the shear strength decreased. PUR adhesive in most cases resulted in the strongest shear strength and MUF
\end{abstract}

\section{Wang $(\bowtie) \cdot$ O. Hagman}

Wood Products Engineering, Luleå University of Technology, Forskargatan 1, 93187 Skellefteå, Sweden

e-mail: alice.wang@1tu.se

\section{B. Sundqvist}

SP Technical Research Institute of Sweden, SP Wood

Technology, Skeria 2, 93177 Skellefteå, Sweden

S. Ormarsson

Department of Civil Engineering, Technical University of Denmark, Lyngby, Denmark

H. Wan

Forest Products Department, Mississippi State University, Starkville, MS, USA

\section{P. Niemz}

Department of Civil Engineering, ETH Zurich, Zurich, Switzerland adhesive resulted in the weakest. MF and PRF adhesives responded to temperature changes in a similar manner to that of the PUR adhesive. The shear strengths of wood joints with PVAc and EPI adhesives were more sensitive to temperature change. At low temperatures, the variability of shear strengths increased with all adhesives. Percent wood failures of joints bonded with different adhesives in most cases were not sensitive to temperature changes.

\section{Introduction}

The building industry is increasingly using engineered wood products such as glued-laminated timber (glulam), laminated veneer lumber (LVL), structural-composite lumber (SCL), and cross-laminated timber (CLT). Engineered wood applications in bridges are also common in Europe and North America. The key issues of these engineered wood products are their adhesive qualities and bondline integrity, which means the adhesive joints in the engineered wood products are supposed to be as strong and durable as the wood itself.

The response of bondlines to temperature changes can affect the integrity of a wooden structure. This knowledge is important in regions and countries, such as Scandinavia, Greenland, the Alps, Canada, Alaska, Russia, Mongolia, northern China, and northern Japan. Wooden constructions in these areas are frequently exposed to low temperatures for a large portion of each year. For instance, using wood (Glulam) for bridges in Russia, northern Europe, and Canada under $-40,-50{ }^{\circ} \mathrm{C}$ is quite common in wintertime. In addition, thermal effects are usually not considered in the design and service life of wooden constructions.

There are some previous studies about the influence of cold temperature on wood properties, including mechanical 
properties (Kollmann and Cote 1968; Geissen 1976; Gerhards 1982; USDA 2010; Jiang et al. 2014; Niemz et al. 2014). They found significant increase of modulus of elasticity, compression and bending strength with decreasing temperature. However, shear strength of wood has never been studied at temperatures below $0{ }^{\circ} \mathrm{C}$. Ispas and Campean (2014) did research on differences in the behaviour during sawing of frozen and unfrozen wood. Freezing rate is considered. Because the slower the freezing rate, the bigger size of the ice crystal formed, the more serious become the micro-fissures (Szmutku et al. 2011).

Wood and adhesives have different properties in terms of swelling and shrinkage. Cured adhesives, for example cured urea-formaldehyde adhesive (Osemeahon et al. 2013), are often brittle. The interaction between wood and adhesive should be studied, especially when the bonded wood products are exposed to large temperature changes. For example, the performance of bondlines at elevated temperatures has been reported (Clauss et al. 2011; Falkner and Teutsch 2006; Frangi et al. 2004). Clauss et al. (2011) found that there were problems at high temperatures with some adhesives. With increasing temperature, the shear strength of solid wood and also of glued wood joints decreased. There were big differences in thermal stability and failure behaviour between the adhesives systems. However, not much information is available on the strength of bondlines at low temperatures, and especially under extremely cold conditions, although studies have been conducted on timber bridges in cold climates (Kainz and Ritter 1998; Wacker 2003, 2009).

The objective of this study was to determine how engineered wood products react when exposed to temperatures ranging from 20 to $-60{ }^{\circ} \mathrm{C}$. In this paper, the shear strengths of Norway spruce wood joints bonded with seven commercially available adhesives were tested at the selected temperatures according to the protocol provided in EN 302-1 (2004).

\section{Materials and methods}

Bondline experiments were carried out on Norway spruce (Picea abies), because it is the most popular species for engineered wood in Scandinavia, although beech (Fagus sylvatica L.) is used in EN 302-1 (2004). Because Norway spruce is not listed in EN 302-1 (2004), results of bondline shear tests of the bonded specimens were compared to the strength of solid wood in shear parallel to grain. To test the bondline integrity under cold conditions, seven different commercially available adhesives from different producers were chosen. These seven adhesives vary in their chemical composition. Most of the adhesives, more specifically polycondensation adhesives like PRF, MF and MUF, have been certified according to EN 301 (2006) and EN 302-1 (2004) standards for application in engineered wood products. In addition, PUR has been certified in EN 15425 (2008). In this study, the shear strength of solid wood and the glued wood joints were tested at different temperatures according to EN 302-1 (2004).

Data were analyzed using the statistical software package IBM SPSS Statistics, Version 20 (IBM Corporation, New York, USA). An analysis of variance (ANOVA) was carried out using a $5 \%$ level of significance. When significant differences were found, Duncan's multiple-range test was performed to reveal any differences caused by the different adhesives at different temperatures. Significant differences are designated by different letters in the tables shown.

\subsection{Materials}

\subsubsection{Wood}

The wood components used for the tests in this study were Norway spruce (Picea abies) with an average oven dry density of $(450 \pm 32) \mathrm{kg} / \mathrm{m}^{3}$ and moisture content (MC) of $(12 \pm 1) \%$. The growth ring angle (angle between growth rings and glued surface of the specimen) of the wood was between $30^{\circ}$ and $90^{\circ}$.

\subsubsection{Adhesives}

The seven adhesives used in this experiment were as follows:

- One-component polyurethane adhesive (PUR).

- Poly(vinyl acetate) adhesive (PVAc).

- Emulsion-polymer-isocyanate adhesive (EPI).

- Melamine-formaldehyde adhesive (MF).

- Melamine-urea-formaldehyde adhesives (MUF1 and MUF2).

- Phenol-resorcinol-formaldehyde adhesive (PRF).

Table 1 demonstrates the adhesive to hardener ratio and operational parameters recommended by the adhesive manufacturers. Although PVAc adhesive is not currently used for the production of load bearing constructions, the adhesive industry is trying to develop PVAc adhesive with crosslinker for structural applications. All manufacturers recommend a one-side application with a spread per side of $200 \mathrm{~g} / \mathrm{m}^{2}$.

\subsection{Methods}

\subsubsection{Production of the specimens}

According to EN 302-1 (2004), the prefabricated boards were stored under standard conditions $\left(20^{\circ} \mathrm{C}, 65 \% \mathrm{RH}\right)$ 
Table 1 Adhesives and optimal gluing process information according to the manufacturer

\begin{tabular}{|c|c|c|c|c|c|c|}
\hline Adhesive & $\begin{array}{l}\text { Adhesive: } \\
\text { hardener ratio }\end{array}$ & $\begin{array}{l}\text { EN 301/302, EN } 15425 \\
\text { certification }\end{array}$ & $\begin{array}{l}\text { Wood moisture } \\
\text { content }(\%)\end{array}$ & $\begin{array}{l}\text { Bonding pressure } \\
(\mathrm{MPa})\end{array}$ & $\begin{array}{l}\text { Pressing time } \\
\text { (Min) }\end{array}$ & $\begin{array}{l}\text { Temperature } \\
\left({ }^{\circ} \mathrm{C}\right)\end{array}$ \\
\hline PUR & - & $\sqrt{ }$ & $\geq 8$ & 0.3 & 30 & 20 \\
\hline PVAc & - & - & $7-10$ & 0.3 & 30 & 20 \\
\hline EPI & $100: 15$ & - & $8-15$ & 0.3 & 30 & 20 \\
\hline MF & 100:100 & $\sqrt{ }$ & $\approx 12$ & 0.3 & 70 & 20 \\
\hline MUF1 & 100:20 & $\sqrt{ }$ & $\approx 12$ & 0.3 & 15 & 90 \\
\hline PRF & 100:15 & $\sqrt{ }$ & $\approx 12$ & 0.5 & 60 & 40 \\
\hline MUF2 & 100:100 & $\sqrt{ }$ & $\approx 12$ & 0.5 & 120 & 20 \\
\hline
\end{tabular}

until an EMC of $12 \%$ was reached. Prior to the bonding process, the boards were planed to a thickness of $5 \pm 0.1 \mathrm{~mm}$ to exclude any ageing effects from the wood surface. Subsequently, the boards were bonded with a close contact bondline $(\approx 0.1 \mathrm{~mm})$ at room temperature at an applied adhesive-spread density of $200 \mathrm{~g} / \mathrm{m}^{2}$. The pressure for all samples was either 0.3 or $0.5 \mathrm{MPa}$ (Table 1). After seven days of storage under standard climatic conditions, the bonded samples were cut into specimens with dimensions of $150 \mathrm{~mm} \times 20 \mathrm{~mm} \times 10 \mathrm{~mm}$ according to EN 302-1 (2004). Figure 1 demonstrates a schematic of a tested sample.

\subsubsection{Solid wood specimen preparation}

To obtain a reference value for the strength of the glued specimens, non-glued solid wood specimens with the same dimensions were tested. These specimens were prepared according to the requirements of EN 302-1 (2004).

\subsubsection{Testing procedure}

The shear strength tests were conducted according to EN 302-1 (2004). To investigate the influence of temperature on shear strength, 15 specimens of each test set were stored in a special climate chamber (Vötsch Industrietechnik vcv7120-5) at the Department of Civil Engineering at the Technical University of Denmark for $12 \mathrm{~h}$ at -20 , $-30,-40,-50$ and $-60{ }^{\circ} \mathrm{C}$ without measurement of relative humidity ( $\mathrm{RH})$. The $20{ }^{\circ} \mathrm{C}$ tests were conducted at $65 \% \mathrm{RH}$ after the samples were conditioned for at least 3 weeks. Tests were executed on a universal testing machine in a climate chamber (Fig. 2) at the designated temperatures. The tests were performed in a position-controlled model with a pull speed of $2 \mathrm{~mm} / \mathrm{min}$. After the shear strength test, the wood failure percentage of each
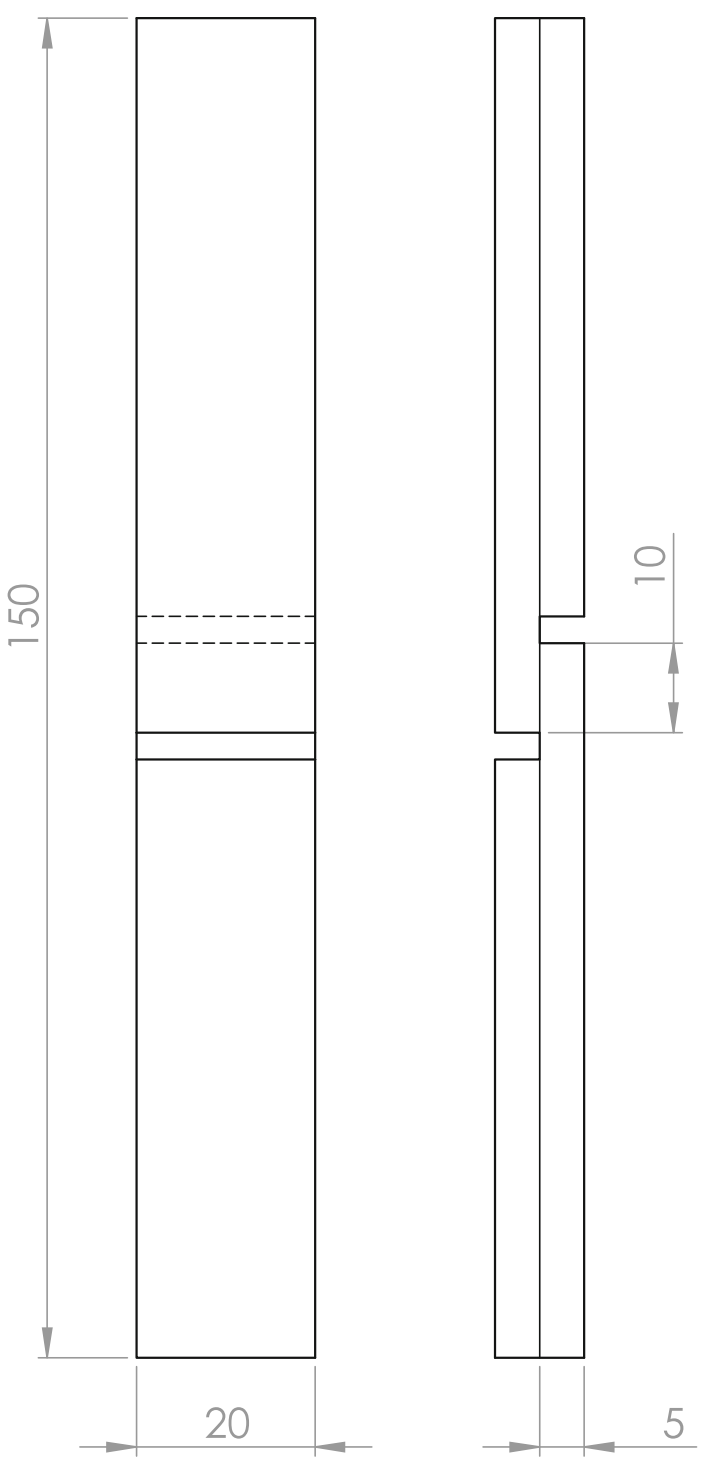

Fig. 1 Schematic of a test sample (adopted from EN 302-1 (2004) Figure 2a) 


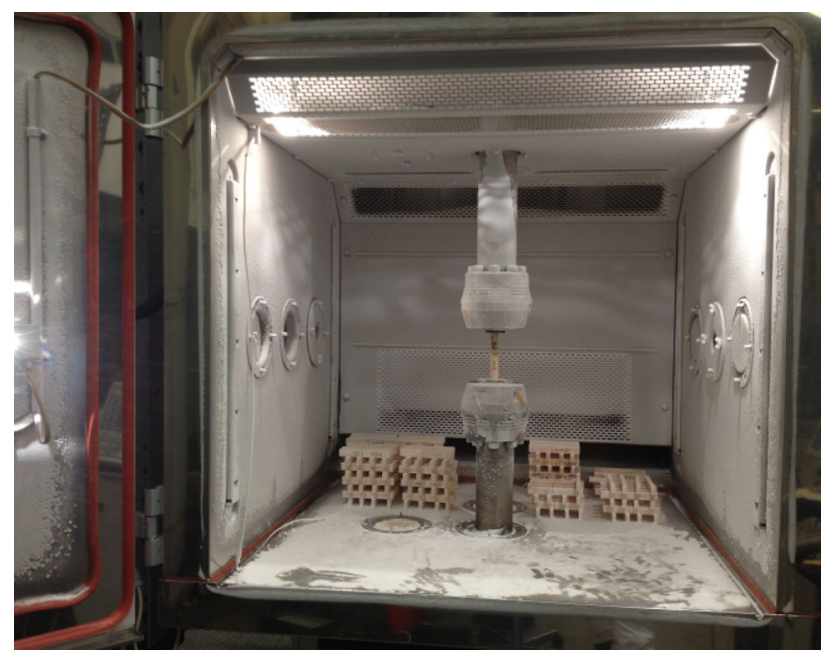

Fig. 2 Climate chamber, shear test machine, and test specimens

tested specimen was estimated visually in a graded scale of $10 \%$ increments, as recommended in EN 302-1 (2004).

\subsubsection{Scanning electron microscope (SEM) analyses of bondlines}

SEM analyses of bondlines were carried out on small sample blocks (ca. $3 \mathrm{~mm} \times 3 \mathrm{~mm} \times 7 \mathrm{~mm}$ ) using a JSM5200 (JEOL, Japan) electron microscope operated at an accelerating voltage of $15 \mathrm{kV}$. Section blocks were prepared on a sliding microtome (Reichert, Austria) and sputter-coated with gold prior to SEM examination.

\section{Results and discussion}

\subsection{Temperature impact on shear strength for each type of adhesive}

Table 2 and Fig. 3 present the shear strength data from wood joints with and without adhesives at different temperatures. The general trend was that as temperature decreased, the shear strength of wood joints both with and without adhesives decreased. Shear strength variability also changed with temperature. Compared to that at $20{ }^{\circ} \mathrm{C}$, the shear strength tested at $-30{ }^{\circ} \mathrm{C}$ had greater variability, indicating that a good quality control of bondline for low-temperature applications was more challenging than for normal temperatures. The wood failure percentages of wood joints with seven types of adhesives at six different temperatures are presented in Table 3. A detailed discussion for each adhesive follows.

\subsubsection{Solid wood specimens}

As temperature decreased from 20 to $-60{ }^{\circ} \mathrm{C}$, the shear strength of solid Norway spruce wood specimens decreased

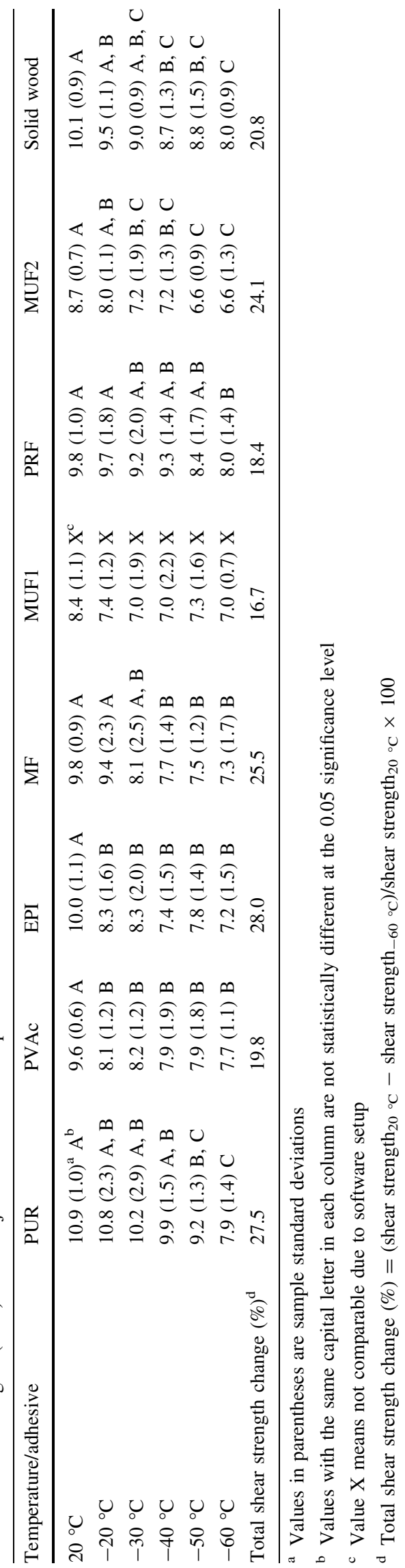


Fig. 3 Bondline shear strength of wood joints bonded with specified adhesives at different temperatures

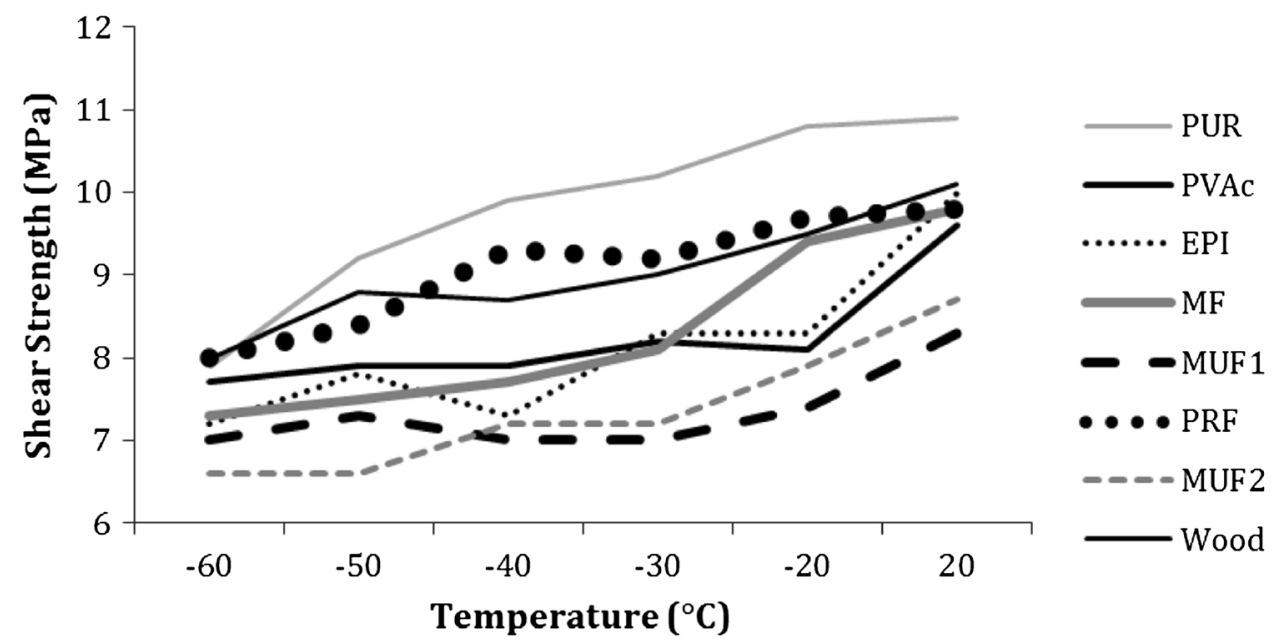

Table 3 Wood failure percentage (\%) of wood joints bonded with different types of adhesives

\begin{tabular}{|c|c|c|c|c|c|c|c|}
\hline Temperature/Adhesive & PUR & PVAc & EPI & $\mathrm{MF}$ & MUF1 & PRF & MUF2 \\
\hline $20^{\circ} \mathrm{C}$ & $77(28)^{\mathrm{a}} \mathrm{A}^{\mathrm{b}}$ & $83(21) \mathrm{A}$ & $83(29) \mathrm{A}$ & $84(16) \mathrm{A}$ & $72(35) \mathrm{A}$ & $71(17) \mathrm{A}$ & 73 (27) A \\
\hline$-20^{\circ} \mathrm{C}$ & 75 (23) A, B & 93 (10) A, B & 82 (24) A, B & 95 (14) A & 69 (41) B & 74 (30) A, B & 76 (37) A, B \\
\hline$-30{ }^{\circ} \mathrm{C}$ & 73 (33) A, B & $92(12) \mathrm{A}$ & 77 (37) A, B & 87 (28) A, B & $55(40) \mathrm{B}$ & 79 (29) A, B & 71 (31) A, B \\
\hline$-40{ }^{\circ} \mathrm{C}$ & $70(36) \mathrm{A}$ & $82(28) \mathrm{A}$ & $74(40) \mathrm{A}$ & $88(26) \mathrm{A}$ & $58(43) \mathrm{A}$ & 79 (25) A & 76 (33) A \\
\hline$-50{ }^{\circ} \mathrm{C}$ & $72(33) \mathrm{A}$ & $83(22) \mathrm{A}$ & $76(38) \mathrm{A}$ & $85(18) \mathrm{A}$ & $91(13) \mathrm{A}$ & $69(30) \mathrm{A}$ & 87 (17) A \\
\hline$-60{ }^{\circ} \mathrm{C}$ & 65 (34) A, B & $86(15) \mathrm{A}$ & $58(27) \mathrm{B}$ & 80 (21) A, B & $55(39) \mathrm{B}$ & 76 (18) A, B & $76(28) \mathrm{A}, \mathrm{B}$ \\
\hline
\end{tabular}

a Values in parentheses are sample standard deviations

${ }^{\mathrm{b}}$ Values with the same capital letter in each row are not statistically different at the 0.05 significance level

from 10.1 to $8.0 \mathrm{MPa}$, a decrease of $20.8 \%$, indicating that temperature changes had a statistically significant impact on wood shear strength. The shear strength parallel to grain decreased significantly and was lower than $10 \mathrm{MPa}$ at $-20{ }^{\circ} \mathrm{C}$, thus not meeting the standard requirement (EN 3012006 ) that was made from beech wood with a density of $700 \pm 50 \mathrm{~kg} /$ $\mathrm{m}^{3}$. This indicates that the impact of low temperature on wood and wood composite products needs further attention, and also addressed the effect of different wood species. Statistically, shear strengths were categorized (based on Duncan test) into three overlapping temperature sectors: (1) 20 to $-30{ }^{\circ} \mathrm{C}$, (2) -20 to $-50{ }^{\circ} \mathrm{C}$, and (3) -30 to $-60{ }^{\circ} \mathrm{C}$. In Sector 1 at $20^{\circ} \mathrm{C}$, the solid wood shear strength was significantly higher than that in Sector 2 at -40 and $-50{ }^{\circ} \mathrm{C}$, and the shear strength in Sector 3 at $-60{ }^{\circ} \mathrm{C}$. This indicates that as temperature dropped, the solid wood shear strength gradually decreased. This result is different from findings by Gerhards (1982) and USDA (2010), both of which used different types of tests. Increasing strength with decreasing temperature has also been found by other researchers (Kollmann and Cote 1968; Geissen 1976; Jiang et al. 2014; Niemz et al. 2014). But they only specified an increase of modulus of elasticity, compression and bending strength with decreasing temperature. Shear strength, however, has never been addressed at low temperatures. Again, it indicates a further research need. As many research papers have indicated that shear strength is the key for engineered wood products, much research is needed to focus on this important issue.

\subsubsection{PUR}

Similar to solid wood, as the temperature decreased from 20 to $-60{ }^{\circ} \mathrm{C}$, the shear strength of tested PUR adhesivebonded wood joints decreased from 10.9 to $7.9 \mathrm{MPa}$, a decrease of $27.5 \%$, indicating that temperature changes had a significant impact on the shear strength of PUR adhesive-bonded wood joints. Statistically, shear strengths were categorized into three temperature sectors with some extent of overlap: (1) $20{ }^{\circ} \mathrm{C}$ to $-40{ }^{\circ} \mathrm{C}$, (2) -20 to $-50{ }^{\circ} \mathrm{C}$, and (3) -50 to $-60{ }^{\circ} \mathrm{C}$. Although the shear strength decreased significantly, there was no significant difference in wood failure percentage, which varied from $77 \%$ at $20{ }^{\circ} \mathrm{C}$ to $65 \%$ at $-60{ }^{\circ} \mathrm{C}$ (Table 3 ).

\subsubsection{PVAc}

As the temperature decreased from 20 to $-60{ }^{\circ} \mathrm{C}$, the shear strength of PVAc adhesive-bonded wood joints decreased 
from 9.6 to $7.7 \mathrm{MPa}$, dropping by $19.8 \%$. Compared to solid wood and PUR adhesive bonds, all of the shear strengths of PVAc adhesive-bonded wood joints were lower at any temperature tested. Statistically, shear strengths were categorized into two temperature sectors with no overlap: (1) $20{ }^{\circ} \mathrm{C}$ and (2) -20 to $-60{ }^{\circ} \mathrm{C}$. The findings show that when temperature decreased from $20^{\circ} \mathrm{C}$ to $-20{ }^{\circ} \mathrm{C}$, the wood joint shear strength dropped significantly, indicating that the shear strength of wood joints with PVAc was sensitive to temperature change. However, when the temperature further decreased from -20 to $-60{ }^{\circ} \mathrm{C}$, the shear strength did not decrease as much. It was also noted that the wood joints bonded with PVAc adhesive were lower than $10 \mathrm{MPa}$ even at $20{ }^{\circ} \mathrm{C}$, not meeting the minimum shear strength requirement of EN 301 (2006). There was no significant difference in wood failure percentage among samples at different temperatures, varying from $83 \%$ at $20{ }^{\circ} \mathrm{C}$ to $86 \%$ at $-60{ }^{\circ} \mathrm{C}$.

\subsubsection{EPI}

Similar to PVAc adhesive, the shear strength of EPI adhesive-bonded wood joints decreased significantly when the temperature decreased from 20 to $-20{ }^{\circ} \mathrm{C}$, indicating that the shear strength developed with the EPI adhesive was sensitive to temperature changes. As the temperature decreased from 20 to $-60{ }^{\circ} \mathrm{C}$, the shear strength decreased from 10.0 to $7.2 \mathrm{MPa}$, dropping by $28 \%$. Compared to solid wood and PUR adhesive bonds, the shear strength of EPI adhesive bonded wood joints was lower at all temperatures tested. Statistically, shear strengths were categorized into two temperature sectors with no overlap: (1) $20{ }^{\circ} \mathrm{C}$ and (2) -20 to $-60{ }^{\circ} \mathrm{C}$. In Sector 2 , as the temperature decreased from -20 to $-60{ }^{\circ} \mathrm{C}$, the shear strength did not decrease much. Similar to the PUR and PVAc adhesive bonds, no statistically significant difference in wood failure percentage could be found at any tested temperature. The value dropped from $83 \%$ at $20{ }^{\circ} \mathrm{C}$ to $58 \%$ at $-60{ }^{\circ} \mathrm{C}$.

\subsubsection{MF}

The shear strength of MF adhesive-bonded wood joints decreased significantly $(25.5 \%)$ when the temperature decreased from 20 to $-60{ }^{\circ} \mathrm{C}$. Compared to solid wood and PUR adhesive bonds, the shear strength of MF adhesive-bonded wood joints was lower at all temperatures tested. Statistically, shear strengths were categorized into two temperature sectors with some overlap: (1) 20 to $-30{ }^{\circ} \mathrm{C}$ and $(2)-30$ to $-60{ }^{\circ} \mathrm{C}$, indicating a relatively good bondline quality developed by MF adhesive, as compared with MUF adhesives (MUF1 and MUF2). The wood failure percentage at different temperatures was not significantly different. It varied from $84 \%$ at $20{ }^{\circ} \mathrm{C}$ to $80 \%$ at $-60{ }^{\circ} \mathrm{C}$.

\subsubsection{MUF (MUF1 and MUF2)}

Due to software issues, it was not possible to compare the impact of temperature on the shear strength of MUF1 adhesive-bonded wood joints. Despite this fact, the data reveal that as temperature decreased from 20 to $-60{ }^{\circ} \mathrm{C}$, the average shear strength decreased by $16.7 \%$. The data showed that as temperature dropped from 20 to $-20{ }^{\circ} \mathrm{C}$, the shear strength dropped rapidly. Further decreasing temperature seems to not affect shear strength. Generally, MUF1 resulted in lower shear strength than solid wood at the temperature range tested. When the temperature changed from -20 to $-60{ }^{\circ} \mathrm{C}$, it did not statistically significantly affect the wood failure percentage, although it dropped from 72 to $55 \%$.

As the temperature decreased from 20 to $-60{ }^{\circ} \mathrm{C}$, the shear strength of MUF2 adhesive-bonded wood joints decreased from 8.7 to $6.6 \mathrm{MPa}$. These values were the lowest of all tested adhesive types. The total shear strength drop was $24.1 \%$. The wood failure percentages at different temperatures were not significantly different from each other and varied from $73 \%$ at $20{ }^{\circ} \mathrm{C}$ to $76 \%$ at $-60{ }^{\circ} \mathrm{C}$. Statistically, the shear strengths obtained were categorized into three temperature sectors with some extent of overlap: (1) 20 to $-20{ }^{\circ} \mathrm{C}$, (2) -20 to $-40{ }^{\circ} \mathrm{C}$, and (3) -30 to $-60{ }^{\circ} \mathrm{C}$, indicating the MUF2 adhesive was relatively sensitive to temperature change.

\subsubsection{PRF}

Conventional PRF adhesive is historically the most established adhesive for cold setting bondline applications. The data in Table 2 indicate that the shear strength of PRF adhesive-bonded Norway spruce did not meet the EN 301 (2006) requirement. This may be due to the bonding parameters selected. As the temperature decreased from 20 to $-60{ }^{\circ} \mathrm{C}$, the shear strength of PRF adhesive-bonded wood joints decreased from 9.8 to $8.0 \mathrm{MPa}$, a drop of $18.4 \%$, indicating that temperature changes had a significant impact on the shear strength. The shear strength changes of wood joints bonded with PRF adhesive at different temperatures was similar to that of solid wood at corresponding temperatures. However, the percentage of wood failures showed no significant differences in the temperature range of 20 to $-60{ }^{\circ} \mathrm{C}$. Statistically, shear strengths were categorized into two temperature sectors with some extent of overlap: (1) 20 to $-50{ }^{\circ} \mathrm{C}$ and (2) -30 to $-60{ }^{\circ} \mathrm{C}$. In Sector 1 at $20^{\circ} \mathrm{C}$, the wood joint shear strength was only significantly higher than that in Sector 2 at $-60{ }^{\circ} \mathrm{C}$, indicating that as temperature dropped, the 
Fig. 4 SEM images of bondlines for wood bonds with seven types of adhesives

\section{bondines for wood bonds with}

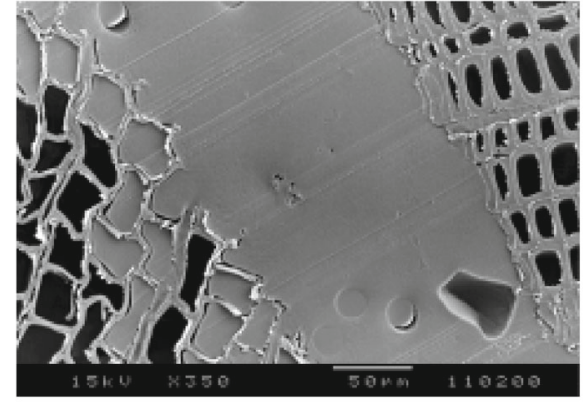

(1) PUR

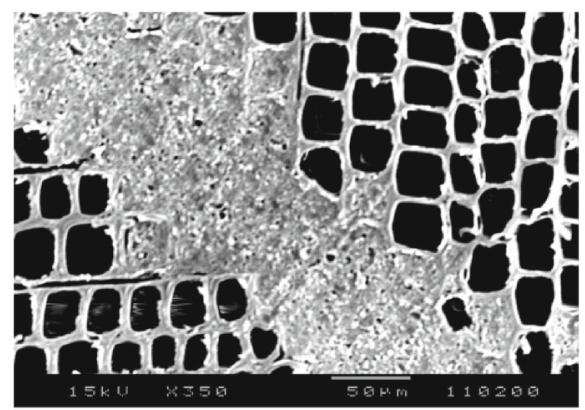

(3) EPI

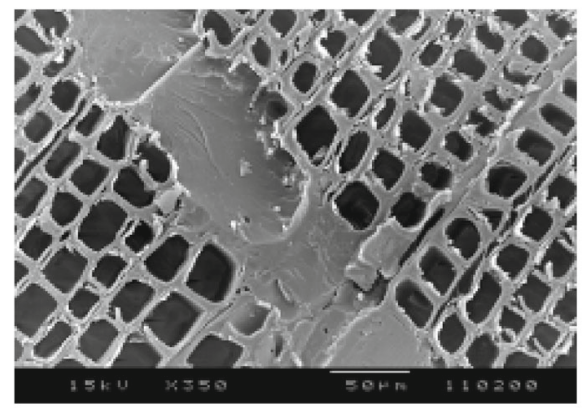

(5) MUF1

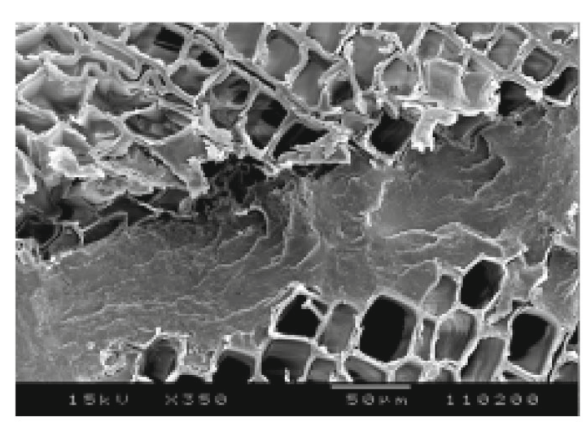

(7) MUF2

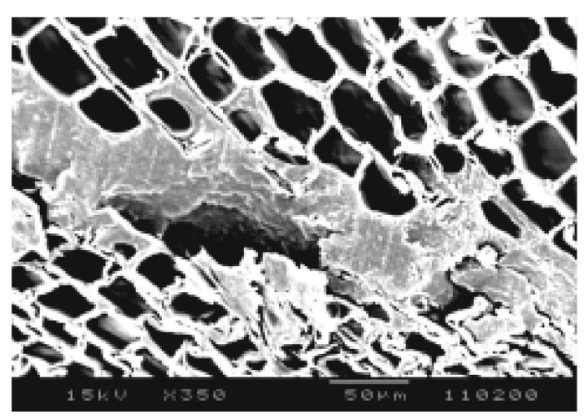

(2) PVAc

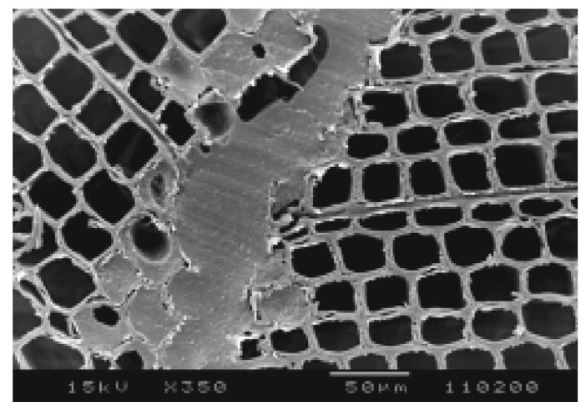

(4) MF

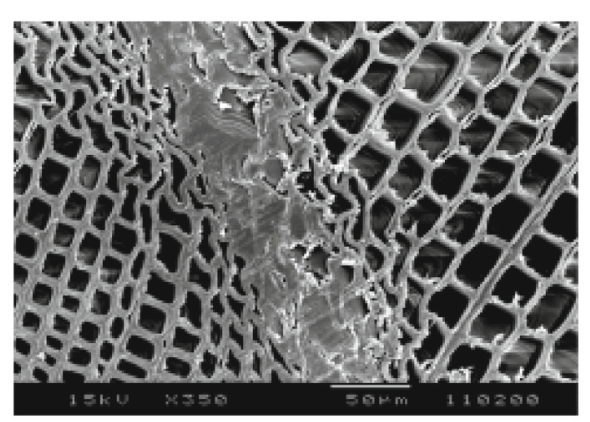

(6) PRF

(6) PRF 
Fig. 4(1), PUR showed the best adhesive penetrations of three lumens; the average bondline width was $178 \mu \mathrm{m}$, much thicker than the designed bondline thickness of $100 \mu \mathrm{m}$. This bondline width was followed by EPI bonds (113 $\mu \mathrm{m})$, MUF2 bonds $(101 \mu \mathrm{m}), \mathrm{MF}$ bonds $(98 \mu \mathrm{m})$, and MUF1 bonds $(83 \mu \mathrm{m})$. The thinnest bondline width of only $65 \mu \mathrm{m}$ was formed by PRF bonds, which may be due to the $0.5 \mathrm{MPa}$ pressure used during specimens' preparation (Table 1). The PRF adhesive could be squeezed out during pressing. It is hard to explain why PRF had the lowest adhesive penetration and where the adhesive was distributed, despite showing strong shear strength. The EPI bondline had many small voids, which may explain why it did not yield stronger shear strength than PUR.

\section{Conclusion}

(1) The shear strengths of Norway spruce wood and PUR, PVAc, EPI, MF, MUF1, PRF and MUF2 adhesivebonded wood joints at temperatures of 20, $-20,-30$, $-40,-50$, and $-60{ }^{\circ} \mathrm{C}$ were studied. Generally, as the temperature decreased, the shear strength of wood and wood joints bonded with different adhesives also decreased. PUR adhesive resulted in the strongest shear strength at most temperatures tested. As temperatures decreased, the shear strength of PUR adhesive-bonded wood joints decreased gradually. MF and PRF adhesives responded to temperature changes similarly to the PUR adhesive. The bondline shear strength of wood joints with PVAc and EPI were clearly sensitive to temperature change. MUF1 and MUF2 adhesives resulted in the lowest shear strengths among the adhesives tested at all temperatures. All adhesive-bonded joints had a reduction in shear strength with decreasing temperature either lower than or equal to that of solid wood control specimens.

(2) At room temperature, the solid wood and all types of adhesives showed relatively low variability in terms of shear strength, while at low temperatures, the shear strength varied considerably more for the different adhesives tested. One possible reason for the increased variability in the cold climate could be that the shear strength of the wood material becomes lower at the same time as the joint samples become more brittle and more sensitive to small variations in geometry and the testing procedure. More formulations should be tested to represent those entire classes of wood adhesives. More specimens are needed in future work to better investigate the effect of temperature change on bondline integrity.
(3) Since the data created by the experiment mostly did not meet the shear strength requirement of EN 301 (2006) and EN 302-1 (2004), especially at low temperatures, it suggests that the influence of low temperatures on diminished shear strength of bondlines for load carrying capacity of glulam should be studied much further. It is important to know the load bearing capacity of the engineered wood, so structures have the proper design value.

(4) Wood failure percentage only showed a few significant differences for certain types of adhesives (MUF1 and EPI) at certain temperatures $(-20,-30$, and $-60{ }^{\circ} \mathrm{C}$ ). That may be because of the character of spruce itself. PUR adhesive showed the best adhesive penetration and the thickest bondline. In the future, research on adhesive films at cold temperatures combined with the influence of moisture contents should also be covered to further investigate this important field of knowledge.

Acknowledgments The authors are grateful for the technical support from Mr. Per Anders Fjellström and Mr. Urban Häggström at SP Wood Technology, Skellefteå, Sweden, and the technicians at the Department of Civil Engineering, Technical University of Denmark, Denmark.

\section{References}

Clauss S, Joscak M, Niemz P (2011) Thermal stability of glued wood joints measured by shear tests. Eur J Wood Prod 69(1):101-111

EN 15425 (2008) Adhesives, one component polyurethane for load bearing timber structures-Classification and performance requirements. European committee for standardization. Brussels, Belgium

EN 301 (2006) Adhesives, phenolic and aminoplastic, for load bearing timer structures-Classification and performance requirements. European committee for standardization. Brussels, Belgium

EN 302-1 (2004) Adhesives for load-bearing timber structures-Test methods-Part 1: Determination of bond strength in longitudinal tensile shear strength. European committee for standardization. Brussels, Belgium

Falkner H, Teutsch M (2006) Load-carrying capacity of glued laminated wood girders under temperature influence. Bautechnik 83(6):391-393

Frangi A, Fontana A, Mischler A (2004) Shear behavior of bond lines in glued laminated timber beams at high temperatures. Wood Sci Technol 38(2):119-126

Geissen A (1976) Über den Einfluss von Temperatur und Holzfeuchtigkeit auf die Elastizitäts- und Festigkeitseigenschaften des Holzes im Gefrierbereich ("Influence of temperature and wood moisture on the elastic and strength properties of timber in freezing range"), Ph. D. dissertation, Universität Hamburg, Germany

Gerhards CC (1982) Effect of moisture content and temperature on the mechanical properties of wood: an analysis of immediate effects. Wood Fiber 14(1):4-36 
Ispas M, Campean M (2014) Experimental research on sawing frozen wood, Bulletin of the Transilvania University of Brasov. Series II. vol 7 (56) No. 1-2014

Jiang J, Lu J, Zhou Y, Zhao Y, Zhao L (2014) Compression strength and modulus of elasticity parallel to the grain of oak wood at ultra-low and high temperatures. BioResources 9(2):3571-3579

Kainz J, Ritter M (1998) Effect of cold temperatures on stresslaminated timber bridge deck, in: J. Natterer and J. L. Sandoz (eds.) Proceedings of the 5th World Conference on Timber Engineering, Swiss Federal Institute of Technology Lausanne, Montreux, Switzerland, Vol 2. pp 42-49

Kollmann FFP, Cote WA (1968) Principles of wood science and technology. I: Solid Wood. Springer Verlag, Berlin

Niemz P, Hug S, Schnider T (2014) Einfluss der Temperatur auf ausgewählte mechanische Eigenschaften von Esche, Buche, Ahorn und Fichte ("Influence of temperature on selected mechanical properties of ash, beech, maple and spruce"). Forstarchiv 85(5):163-168
Osemeahon SA, Maitera ON, Hotton AJ, Dimas BJ (2013) Influence of starch addition on properties of urea formaldehyde/starch copolymer blends for application as a binder in the coating industry. J Environ Chem Ecotoxicol 5(7):181-189

Szmutku MB, Câmpean M, Sandu AV (2011) Microstructure modifications induced in spruce wood by freezing. Pro Ligno $7(4): 26-31$

USDA (2010) Forest Products laboratory. Wood Handbook: wood as an engineering material. General Technical Report FPL-GTR190. Madison, WI: U.S. Department of Agriculture, Forest Service, Forest Products Laboratory. 5-36 p

Wacker JP (2003) Cold temperature effects on stress-laminated timber bridges-A laboratory study, Res. Pap. FPL-RP-605. Madison, WI: U.S. Department of Agriculture, Forest Service, Forest Products Laboratory. $22 \mathrm{p}$

Wacker JP (2009) Performance of stress-laminated timber highway bridges in cold climates, In: Proceedings of the 14th conference on cold regions engineering, 2009 August 31-September 2: Duluth, MN: pp 637-649 